\title{
A interrupção da democracia. O Cone Sul
}

\section{The Interruption of Democracy. The Southern Cone}

\author{
Guilherme Castelo Branco ${ }^{1}$
}

\begin{abstract}
Resumo: No é de hoje que vivemos numa tensão constante e repleta de movimentos pendulares entre experiencias democráticas e antidemocráticas, tanto no Brasil como em toda a América Latina. No Cone Sul, desde o século XIX, os movimentos de independencia e os interesses de certos segmentos sociais das elite que defenderam um modelo oligárquico de democracia foram quase sincrônicos. A partir do final do siglo XIX vimos dobrarem-se uma sobre a outra -com um alicerce político político bastante frágil e precario- duas formas de exercício democrático: as baseadas nas oligarquias ou por medio de estruturas socioeconômicas competitivas. A iminência do retorno à extrema desigualdade social no século XXI, no Conoe Sul, sem embargo, não parece ser un fato consumado. Na América do Sul, muitos movimentos mostraram sua potência na luta agonística, particularmente nos movimentos populares integrados por habitantes de favelas e bairros pobres, com um rosto renovado: movimentos de raça, de gênero, ecológicos, entre outros, enfin, numerosas propostas políticas. Deste modo, os movimentos populares e os partidos políticos democráticos se fortaleceram no combate com o capitalismo colonial e neo-selvagem que busca ocupar um espaço crescente no continente sul americano.
\end{abstract}

Palavras chave: democracia, estado de exceção, violência de estado, participacão democrática, lutas agonísticas.

\begin{abstract}
Since immemorial times, we live in a constant tension in Brazil and in the whole Latin America, between democratic and anti-democratic experiences. In the Southern Cone, the movements of independence and the yearnings of certain elite social segments that defended a oligarchic model of democracy, beginning in the nineteenth century, were almost synchronous. From the end of the nineteenth century we saw two forms of democratic exercise, based on the oligarchies being in the competitive socioeconomic structures, with very fragile and precarious political foundations. The imminent return to the extreme social inequality in the 21st century in South America, however, does not seem to be a fait accompli. Many movements have proved to be powerful in the agonistic struggle, led by slum dwellers and miserable neighborhood residents: popular movements with new faces, like movements of race, gender, ecology, and, at last, a large number of political proposals. Popular movements and democratic political parties have strengthened in the fight against colonial and neo-selvagem capitalism that seeks to occupy growing space in the South American continent.
\end{abstract}

Keywords: democracy; exception state; state violence; democratic participation; agonistic struggles.

\footnotetext{
${ }^{1}$ Docente Catedratico da Universidade Federal do Rio de Janeiro. Pesquisador da FAPERJ. Membro da Red Iberoamericana Michel Foucault. Membro da Red Iberoamericana de Filosofia Política.
} 
A história da filosofia política é longa. A história das democracias, todavia, são muito breves. No passado, na Grécia Clássica, a experiência histórica da democracia, com as restrições conhecidas, durou muito pouco. Foram poucas décadas nas quais que essa experiência de decisão pessoal e direta de parcela da população teve lugar na história. Logo depois foi tornada uma farsa por conspiradores e oportunistas, da época. Mais à frente, foi a história truculenta de sempre. Não sem motivo, o tempo da democracia grega na Idade Clássica gerou um extraordinário encantamento, cujas narrativas foram fixadas na memória política e nos sonhos de todos os partidários de um modo de vida participativo, autônomo, sem restrições de locomoção e impedimentos no campo da expressão. Muitos séculos, milênios depois, a democracia voltou com nova configuração, tal como a conhecemos na modernidade. Em nossa época, no mundo atual, em territórios cujos contornos são muito difíceis de delimitar, a democracia tem pouco mais de 140 anos.

Esqueçamos as teorias históricas sobre a continuidade da democracia ao longo do tempo, pois é coisa sem nexo, difícil de sustentar. Da Grécia antiga, passando pela idade média, pela acumulação do capital, pela Revolução Francesa, vivemos longos períodos, milênios, sem democracia nenhuma. Os partidários da vida comunitária e democrática, há dois séculos, tem procurado realizar, malgrado as experiências das diversas ditaduras e regimes totalitários, alguns esforços a favor da gestão democrática das sociedades. A pergunta que se faz é pertinente: será que, de fato, o mundo contemporâneo realiza, de modo crescente e permanente, uma vida democrática feita através de ampla participação popular, em todos os aspectos? Se a democracia, de fato, existe com ampla participação popular, qual seria a razão das eventuais e constantes destituições da vida comunitária e democrática em todo o mundo?

Seria a democracia uma exceção? Seria a democracia uma experiência fugaz e inconsistente? Ou, podemos nos perguntar, -a vida em democracia seria uma heterotopia- uma experiência muito estranha, inusual, uma vida política que se dá numa cena político-social transitória, vulnerável e que pode, eventualmente e ao sabor dos interesses dos poderes econômicos e de mandamentos truculentos, de toda ordem, ser desfeita? A democracia é uma esperança sem apoio, na estrutura legal, que pode se valer na vida participativa? Podemos acreditar no ideal da democracia, na fórmula em que conhecemos?

Nosso tema tem como foco o continente ao Sul da Europa, explorado e com experiência verdadeira de sermos vítimas de genocídio enquanto habitantes da terra. O ponto de partida dessa análise é o Cone Sul. Não é de hoje que vivemos numa tensão constante e repleta de movimentos pendulares (depois da época colonial), entre experiências democráticas e antidemocráticas na América Latina. Não deixa de ser impressionante o fato de que o Novo Mundo não tenha feito dos ideais de república e de democracia uma experiência comunitária com amplo valor político, com vigor. Afinal, éramos colônias, vivíamos à distância da sede dos impérios e sem qualquer 
parâmetro jurídico conservador ou violência étnica consolidada, sem ter as mazelas das monarquias e estruturas estamentais da Europa. Mas nossas experiências históricas se mostraram muito pouco exitosas, no que se refere à participação do povo na política.

As hipóteses sobre a razão de ser do constante fracasso em dar continuidade às propostas e vivências da participação popular, no nosso mundo americano, e democrática são muitas. Michel Foucault -quem sabe?- talvez tenha explicado este fenômeno, no campo da teoria: ele insinuou, no Securité, térritoire population, que os conceitos(ou verbetes) dos enciclopedistas sobre a República e Democracia Moderna possuíam uma contradição fundamental no que diz respeito à representação democrática: eles aliavam, a seu ver, a associação democrática à antiga ideia de liderança dos melhores representantes da sociedade. Associava, de um único golpe, Maquiavel com Rousseau. ${ }^{2} \mathrm{O}$ enciclopedismo, deste modo, estava mais próximo do modelo mercantilista do que do modelo liberal e, na verdade, realizou uma inusitada e singular aliança entre o velho modo de fazer política com o liberalismo, enquanto face do capitalismo em política nos quais os bem-nascidos ou bem-sucedidos devem ser detentores do poder, e a proposta de representação política se explicita como vida participativa entre os membros da comunidade dos iguais na elite. Até mesmo na teoria tal vinculação não faz sentido, pois este projeto de democracia nada mais é que uma comunidade de privilegiados, sob uma roupagem demagógica. Todos nós sabemos: um canguru não pode acasalar com um elefante.

A história política do Cone Sul, na hipótese que apresento ${ }^{3}$, decorreu, no campo das ideias, do uso "oportuno" da Enciclopédia, pelos senhores das classes dirigentes das américas. A Enciclopédia instigou a imaginação das classes dominantes das américas, que enxergaram na proposta de democracia apresentada nos volumes extensos e inacessíveis às camadas pobres, e deliberadamente sem instrução, da população, que converteu-se num instrumento de legitimação do controle político autônomo, nacional e, o que era mais importante à época (para os membros das castas abastadas), com contornos territoriais, nos quais teriam, respectivamente, poder e controle.

No Brasil e na América Latina, os movimentos de independência e os anseios de certos segmentos sociais das elites econômicas (grandes proprietários rurais, a oligarquia no sentido próprio da palavra, e também uma certa burguesia em gestação) que defenderam modelos oligárquicos de democracia, a partir do começo no século XIX, foram quase sincrônicos. No final do século XIX, na sequência dos diversos movimentos de independência, vimos que se articularam, como por uma dobra, com alicerces políticos bastante frágeis e precários, duas formas de exercício democrático, baseados seja nas oligarquias seja em estruturas socioeconômicas competitivas e dissimétricas. Não deixou de ser algo novo em política. Era o início de um tempo inicial de evidente e prolongada impostura em política democrática. Em pouco tempo, no decurso no século XX, no Cone Sul, passamos a viver, em dezenas de países, de todos

\footnotetext{
2 Ver Sécurité, Térritoire, population, aula de 1 de fevereiro de 1978.

${ }^{3}$ E que é uma variante de outras hipóteses históricas possíveis na América Latina.
} 
os tamanhos, uma longa série de democracias restritivas e sem participação ampla, que são simulacros da ideia de democracia universal oriunda de ampla participação popular. Não sem sentido, vale a pena observar que estas democracias sem vínculo com a vida das pessoas se disseram amparadas no nosso modelo distante, o Velho Mundo, na qual, alegou-se, certamente sem razão, sempre vigorou a democracia na Europa.

Por outro lado, devemos fazer uma interrupção; na verdade, não podemos deixar de enfatizar que as interrupções da curta história das democracias contemporâneas não é privilégio na América Latina. Censurar a América Latina por suas mazelas políticas, pelos seus constantes golpes militares, por suas instabilidades, é desmerecer o papel constante dos déspotas e oportunistas na vida europeia. A Europa realizou, na sua quase totalidade e extensão territorial, um vasto campo de experiências antidemocráticas, com o traço característico de que essas histórias de autoritarismo e totalitarismo tem longa duração, muito mais que nas Américas. As Américas são relativamente velozes em se desvencilhar das suas ditaduras genocidas. As ditaduras no Cone Sul são assassinas e e no geral, breves, com poucas exceções. $\mathrm{Na}$ Europa, constatamos algo muito diferente: os tiranos e ditadores truculentos, duradouros e sem limites na Europa tem nomes incontestáveis: Salazar, em Portugal, Franco na Espanha, Stalin nas Repúblicas Soviéticas, Hitler na Alemanha, Tito na Iugoslávia, Ceseascu na Romênia, eis alguns poucos exemplos de uma longa lista de oligarcas e tiranos europeu, bem diferentes das neoditaduras/golpistas existente na Américas. No Velho Mundo a desfaçatez, a manipulação de segmentos apolíticos da população e a falta de respeito diante dos anseios populares organizados também são um fato incontornável e que são técnicas e mídias que apoiaram os regimes despóticos. Será que a Espanha não está neste processo, agora, de modo explícito? O que me espanta é a duração das experiências despóticas, que perduraram em tempos de consolidação das democracias possíveis no tempo recente. Neste exato momento, no conflito (de 2017) com a experiência da Catalunha, o despotismo espanhol está mostrando sua face.

O caráter frágil das democracias, no Cone Sul, talvez tenha se iniciado e tenha sua identidade facilmente mutável nas Constituições e legislações das Repúblicas, desde o século XVIII, como Foucault analisa no Sécurité, territoire, population: é constitutivo das novas gestões do Estado contemporâneo a possibilidade de se romper a ordem jurídico-política, a partir de iniciativa do próprio Estado, criando condições para o estado de sítio, para o estado de exceção, para a violência de Estado. Giorgio Agamben se apropria da indicação foucaultiana e sustenta, categoricamente, que

«O totalitarismo moderno pode ser definido, num determinado sentido, como a instauração, pelo estado de exceção, de uma guerra civil legal...» (Agambem, 2003, p. 11)

Frédéric Gros, por sua vez, no Le Principe Sécurité, sustenta ao longo do livro que vivemos em ordens políticas regidas por estados de segurança, conceito que possui grande espectro e descreve diversas maneiras de funcionamento, na prática, de 
estruturas de controle das subjetividades, das sociedades, a partir dos blocos econômicos.

Mas não podemos negar: as estruturas políticas, no cone sul, sempre estiveram ao sabor das circunstancias e dos casuísmos sobretudo de natureza economia mundiais, com poucas e esporádicas exceções. Nós vivemos (será que apenas no Cone Sul?) em falsas democracias, e por consequência muito vulneráveis, sem amparo de estruturas legitimadoras da vida política democrática consistente. Como afirma Wanderley Guilherme dos Santos, cientista político brasileiro:

«Compreender de forma adequada a diferença entre sociedades de oligarquias representativas e sociedades de democracia representativa contribui para a percepção da sutileza de formas incompatíveis de violação da competição democrática». (Santos, 2017, pag. 25)

Há modos diferentes de democracias representativas. As nossas democracias, no Cone Sul, são descaradamente oligarcas. O Novo Mundo, enfim, vive em constante oscilação no campo político, como é o que se passa hoje, com o renascimento da neo-direita e de governos conservadores. A qual tipo de democracia representativa estamos majoritariamente vinculados? Voltamos ao regime oligarca, ou temos outro tipo de regime político em curso?

A breve história das democracias sempre revelou barreiras à participação das pessoas e grupos sociais na vida democrática. No importante texto de Danielle Caramini, são apresentados inúmeros instrumentos restritivos à participação popular no decurso dos séculos XIX e XX. O primeiro deles é o de ordem econômica: em certos países, não ter posses e dinheiro era motivo para o impedimento do voto e da candidatura. (EUA, etc). Outro caso foi a origem racial (como nos EUA). A religião também foi motivo de impedimento. Outro caso é a faixa etária, que foi se modificando ao longo do século Xx: na Itália, por exemplo, a idade mínima, outrora, era de 30 anos. Outro importante motivo de restrição foi gênero: o voto das mulheres, durante muito tempo, foi criminalizado e impedido. Outro motivo, não menos importante e controverso, foi o grau de instrução: em muitos lugares havia uma barreira relativa ao nível de comparecimento ao ensino formal. Acrescenta-se a estas restrições, vejam, duas que são muito difíceis de avaliar: grau de civilidade e estado civil.

O mais importante, todavia, é que em muitas partes do mundo um número significativo de pessoas, até pouco tempo atrás, não conheceram o voto popular na sua fórmula de universalização do direito de votar. Nas repúblicas soviéticas, até os anos 1970, não existia escrutínio popular, tal como o conhecemos, apesar de ignorados em certas circunstâncias. A Espanha, minhas homenagens, segundo pesquisas, somente universalizou o voto em $1977^{4}$. Em muitos lugares, e isto talvez seja muito bom, é desnecessário acontecerem eleições, e nunca houve denúncias sobre o caráter despótico da vida comunitária.

\footnotetext{
${ }^{4}$ O primeiro país a estabelecer a universalização do voto, em 1983, foi a Nova Zelândia.
} 
Vivemos, de modo diferente, na América Latina, uma condição intermitente ou constante de violência de Estado, que tem sido fator de seguidas crises políticas e rupturas institucionais nas Américas. No presente momento, o que estamos assistindo, em nosso continente, neste início de século XXI, é o soerguimento da extrema direita metamorfoseada de neo-liberalismo, com o desmantelamento das frágeis e recentes legislações trabalhistas e previdenciárias, e o objetivo dos grupos conservadores é a restauração do quadro social de dependência ao capitalismo de grande porte e o retorno à pirâmide social com pronunciada camada inferior. Seriam os neo-escravos que esta direita quer criar novos replicantes, como num filme de ficção científica?

$\mathrm{Na}$ nossa era da governamentalidade, o mundo democrático e neoliberal, que viria da decisão popular, das práticas correntes de mercado e de participação política, e que consubstancia as leis, seria um mundo da gestão dos interesses dos diversos setores da população, considerada enquanto categoria cujos direitos de opinião são levados em conta. Seria assim tão fácil, um mero populismo, de caráter demagógico? Tudo seria fácil, se não entrasse em jogo a ideia de golpe de Estado, ou seja, a ideia de que a governamentalidade traz em si mesma um aspecto absolutamente inusitado: na hipótese de ocorrerem certas condições excepcionais, de ameaça (real ou imaginária) ao poder instituído e à segurança, a partir daí se inicia o golpe de estado, entendido de enquanto iniciativa e ação feitos pelo próprio Estado. $^{5}$

O golpe de Estado obedece a princípios jurídicos e está quase sempre presente sua possibilidade nas cartas magnas. O golpe de Estado consiste numa suspensão, numa paralização das leis e da legalidade. O golpe de Estado ultrapassa e excede o direito comum. Na modernidade, o Estado, em seu exercício racional e gestor das instituições deveria ter um caráter absolutamente administrativo e mediador; entretanto pode passar a ter um rosto completamente diferente, segundo suas conveniências:

«quando a necessidade exige, a razão de Estado converte-se em golpe de Estado, e, neste momento, é violenta». (Foucault, 2004, pág. 269)

Tal violência, ademais, é e deve ser teatral ${ }^{6}$, não somente para impactar, mas também para mostrar que sua intervenção tem por meta ser durável ou irreversível. Tal análise de Foucault, num certo sentido, perdeu seu valor e alcance.

No Cone Sul, todavia, inovamos, realizando golpes de Estado cuja violência tem outra forma e manifestação. Como o golpe de Estado nada mais é do que a manifestação da razão de Estado, temos que admitir que não existe antinomia, no que concerne ao Estado, entre razão e certo uso da violência. Ao fim e ao cabo, a noção de golpe de estado é inerente ao Estado e ao sistema legal. Tal poderia ser o

\footnotetext{
${ }^{5}$ Neste caso, temos de deixar claro que golpe de Estado é sinônimo de estado de sítio ou estado de exceção, situação que se desencadeia por dispositivos constitucionais e que é realizado pelo próprio Estado, em caso de ameaça (real ou fictícia) externa ou interna. Através da noção de golpe de Estado torna-se perfeitamente cabível que façamos a associação entre Golpe de Estado e Terrorismo de Estado.

${ }^{6}$ Como bem mostra Roberto Nigro, no seu texto "Terrorisme d'état, coup d'état, exclusion", traduzido para o português brasileiro no livro Terrorismo de Estado.
} 
caso do que na linguagem comum, chamamos no Cone Sul de «golpe parlamentar». Os mandatários e executores deste novo tipo de golpe não são militares, mas empresários, setores do mundo político, a grande mídia, assim como segmentos não organizados da sociedade. Em resumo, no golpe parlamentar os derrotados realizam a substituição fraudulenta dos governantes eleitos, sob alegação de violação de procedimentos administrativos. Tudo se passa em nome da lei, seguindo processos institucionais feitos a partir de interpretações bizarras sobre a vida institucional e a ordem jurídica. A primeira variante deste tipo de golpe ocorreu no Paraguai. Com grande exibição de notícias contrárias ao governo a ser deposto, a aliança dos conspiradores utiliza-se da premissa dos princípios democráticos para realizar a interdição de governos eleitos e legítimos. A cada dia que passa, vemos a autofagia da democracia totalitária se consumar. A partir de 2016, no Brasil, com parâmetros muito especiais, experimentamos um golpe parlamentar.

Estamos vivendo, no Continente Sul, ao retorno à extrema desigualdade social que vigorava no passado e que procura voltar a acontecer com o renascimento da pobreza dos operários, no século XX. No Cone Sul, todavia, o retrocesso na vida social e política não parece ser fato consumado. Nada na historia fornece verdades acabadas. O processo histórico não dá voltas para o passado, e, no caso da América do Sul, muitos movimentos tem se revelado significativos na luta agonística: os movimentos populares com nova face, movimentos de raça, de gênero, ecológicos, de moradores de favelas e bairros miseráveis, enfim, um grande número de propostas políticas tem mostrado sua face. Multifacetados, com diferentes palavras de ordem, mas nem por isto microscópicos, movimentos populares e grupos políticos de esquerda tem se fortalecido no combate ao capitalismo neo-selvagem que procura ocupar espaço crescente no continente sul-americano.

Para finalizar darei apenas um exemplo, oriundo de um mesmo contingente social: as favelas ou comunidades afrodescendentes, ${ }^{7}$ onde existem movimentos de resistência, como o localizado no Rio de Janeiro e integrado a um sem-número de movimentos populares similares, a “Comunidade Quilombola ${ }^{8}$ Pedra do Sal”, que é uma comunidade de ex-escravos, de origem africana, e que procura, há mais de cem anos, preservar seu direito a manter seu modo de vida e sua cultura, à diferença das imposições dos preceitos culturais e econômicos dos estadunidenses e europeus. $\mathrm{O}$ campo de resistência aberto pela comunidade, é profundo: suas raízes não se prendem a motivos rasos e frívolos: os militantes e participantes deste modo de vida comunitário defendem suas origens africanas, e seus direitos como vítimas da escravatura.

\footnotetext{
7 Caso antitético é a CUFA (Central Única das Favelas), que ao longo de sua existência tornou-se uma organização voltada para a formação de empreendedores, seguindo a lógica do neoliberalismo. Agora seu caráter neo-liberal tornou-se mais explícita e seu grupo solicitou a criação de um Partido de Favelados, partido político de caráter oficial e que receberá dotações estatais e verbas.

${ }^{8}$ Quilombo foi o nome dado no Brasil aos locais de refúgio dos escravos durante o período colonial. Nesses locais, ex-escravos passavam a viver em liberdade, criando novas relações sociais. Muitos quilombos existiram no Brasil e centenas deles ainda existem, formando o que hoje é chamado de comunidades quilombolas. Os quilombos são espaços sociais de resistência contra a escravidão, no passado e no presente.
} 
O "Coletivo Criola", por sua vez, movimento de mulheres em lutas por seus direitos na sociedade, no trabalho e na vida, é vinculado ao movimento quilombola da Pedra do Sal, mas com autonomia e independência. É um movimento complexo e fora da agenda neoliberal; além de vincular movimento feminista, de luta pelos direitos de cidadania, de luta pelo direito à saúde e a atividades econômicas alternativas, de direito à participação em cultos de origem africana, o movimento faz da vida, nada fácil, das mulheres associadas ao coletivo, um trabalho constante de empoderamento e autoestima que vai na contramão das políticas oficiais conservadoras.

Para nós no Brasil, o grande desafio é a transformação política, a recriação constante da vida comunitária e associativa, a criação de uma nova agenda política, com outras pessoas, e com um pensamento intransigente, que faz da razão e da ação instrumentos de lutas de resistência.

\section{REFERÊNCIAS BIBLIOGRÁFICAS}

Agambem, G. (2003). État d'Exception. Homo sacer, II,1. Paris: Ed. du Seuil. Arendt, H. (2014). As origens do totalitarismo. São Paulo: Companhia das Letras. Camarani, D. (2000). The Societies of Europe: Elections in Western Europe since 1815. Reino Unido: Macmillan Reference.

Catelo Branco, G. (org.). (2009). Terrorismo de Estado. BH, Minas Gerais: Ed. Autêntica. - (2015). Michel Foucault: filosofia e biopolítica. Belo Horizonte: Ed. Autêntica.

Corrêa, M. L. (2016). Quilombo Pedra do Sal. Belo Horizonte: FAFICH.

Gros, F. (2012). Le Principe Securité. Paris: Gallimard.

Duarte, A. (2009). Foucault e as novas figuras da biopolitica: o fascismo contemporâneo in Para uma vida não-fascista (Orgs. Margareth Rago, Alfredo Veiga-Neto). Belo Horizonte: Ed. Autêntica.

- (2010). Vidas em Risco: crítica do presente em Heidegger, Arendt e Foucault. Rio de Janeiro: Forense Universitária.

Foucalt, M. (1976). Histoire de la Sexualité I. La Volonté de Savoir. Paris: Gallimard.

- (1994). Dits et écrits. 1954-1988. Paris: Gallimard. 4 vols. Orgs. D. Defert, F. Ewald e J. Lagrange. Paris: Gallimard.

- (1997). Il faut defendre la societé. Paris: Ed. du Seuil.

- (2004a). Naissance de la biopolitique. Paris: Ed. du Seuil.

- (2004b). Sécurité, territoire, population. Paris: Ed. du Seuil.

- (1996). Genealogia del racismo. La Plata: Altamira.

Santos, W. G. (2017). A democracia impedida. O Brasil no século XXI. RJ: FGV Editora.

Werneck, J (org.) Mulheres Negras: um Olhar sobre as Lutas Sociais e as Politicas públicas no Brasil. Rio de Janeiro: Grupo Criola. 